\title{
Recovery and long term functional outcome in people with critical illness polyneuropathy and myopathy: a scoping review
}

\author{
Domenico Intiso ${ }^{1 *}$ (D), Antonello Marco Centra ${ }^{1}$, Michelangelo Bartolo ${ }^{2}$, Maria Teresa Gatta', \\ Michele Gravina ${ }^{1}$ and Filomena Di Rienzo ${ }^{1}$
}

\begin{abstract}
Background: Intensive care unit acquired weakness (ICUAW), embraces an array of disorders labeled "critical illness polyneuropathy" (CIP), "critical illness myopathy" (CIM) or "critical illness polyneuromyopathy" (CIPNM). Several studies have addressed the various characteristics of ICUAW, but the recovery is still unclear.

Objective: The present review investigated the recovery and the long-term functional outcome of subjects with ICUAW, whether the types of ICUAW have different outcomes and whether there is any supporting evidence.

Methods: Literature search was performed from MEDLINE/PubMed, CINAHL, EMBASE, PeDro, Web of Science and Scopus. Inclusion criteria were: i) sample size including five or more subjects; ii) subjects who suffered from ICUAW and/or CIP, CIM and CIP/CIM; iii) ICUAW ascertained by EMG. Follow-ups longer than one year were defined as long-term.

Results: Twenty-nine studies met the inclusion criteria. In total, 788 subjects with ICUAW were enrolled: 159 (20.1\%) died and 588 (74.6\%) were followed. Of all the included patients, 613 (77.7\%) had CIP, 82 (10.4\%) CIM and 56 (7.1\%) CIP/CIM. Overall, $70.3 \%$ of the subjects with ICUAW fully recovered. Seven (24.1\%) studies had a follow-up longer than 1 year (range 2-8) with 173 (21.9\%) subjects enrolled globally and 108 followed. Of these subjects, 88.8\% gained full recovery. Most of the studies did not use proper functional scales and only 4 and 3 studies employed the Barthel scale and the Functional Independence Measure (FIM) scale. Differentiation between the types of ICUAW was performed in 7 studies, but only 3 studies reported that subjects with CIM had a better prognosis and earlier recovery than subjects with CIP/CIM.
\end{abstract}

Conclusions: Subjects with ICUAW could achieve good recovery and could improve at follow-up. However, the quality of the published studies due to short follow-ups and the paucity of defined outcome measures require confirms.

Keywords: Critical illness polyneuropathy, ICU acquired weakness, Functional outcome, Rehabilitation

*Correspondence: d.intiso@operapadrepio.it; d.intiso@alice.it 1 Unit of Neuro-Rehabilitation and Rehabilitation Medicine, IRCCS "Casa Sollievo della Sofferenza", Viale dei Cappuccini, 71013 San Giovanni Rotondo (FG), Italy

Full list of author information is available at the end of the article

\begin{abstract}
Introduction
A number of studies have been published about the muscle weakness that may affect intensive care unit (ICU) survivors. This disorder, which in the intensive care literature is better known as ICU acquired weakness (ICUAW), embraces a spectrum of clinical conditions. All of these conditions show variable levels of muscle strength impairment, from weakness to paralysis, which
\end{abstract}


involve, bilaterally, the upper and lower limbs of ICU subjects. Although the clinical pictures are generally indistinguishable, ICUAW encompasses different pathological forms that damage the muscular and the peripheral nervous system. Different types of this pathology have been described and labeled according to the histological aspects and the electrophysiological findings and depending on the predominant structure involved. In particular, the definitions include: i) critical illness polyneuropathy (CIP), if the peripheral nervous system is affected; ii) critical illness myopathy (CIM), if the muscles are involved, and iii) critical illness polyneuropathy and myopathy (CIP/CIM), critical illness neuromyopathy [1], and polyneuromyopathy (CIPNM) [2, 3], if the pathological process affects both muscles and nerves. Although ICU specialists prefer to use the term ICUAW, the definition "critical illness polyneuromyopathy" (CIPNM) is widely diffuse, but for the purposes of the present study, ICUAW term was used. After the first description by Bolton et al. at the beginning of the' $80 \mathrm{~s}$ [4], a number of studies have been published that have contributed to making remarkable advances in the understanding of the complex aspects of ICUAW, such as the electrophysiological [5] and histological features [6] as well as the pathogenic mechanisms. The occurrence of this disorder has been variously detected with a range from 45 to $80 \%$ [7-9]. A systematic review reported a median prevalence of $43 \%$ [10]. Furthermore, many risk factors have been suggested to favor the development of ICUAW, including sex (female), sepsis, ICU length of stay and multiple organ failure $[11,12]$. Several therapeutic approaches and strategies have been proposed and evaluated for the management of ICUAW subjects, but pharmacological treatments have failed to prevent the occurrence and were ineffective in treating the disorder [13-15]. However, recent reviews and meta-analyses have demonstrated that early mobilization is associated with a lower likelihood of developing this clinical condition [16, 17]. Some reviews have addressed the various aspects of ICUAW, but they have not highlighted recovery, functional outcome and quality of life [18-20]. Despite the lack of treatments and the limitations of rehabilitative strategies, it was reported that $55-70 \%$ of subjects reached a full recovery after ICU discharge [21, 22], and that recovery depended on the type of ICUAW, as confirmed by the fact that CIM had an earlier and better functional outcome than CIP [22, 23]. In 2005, an extensive literature review of the neuromuscular sequelae of ICU subjects with critical illness reported that $68.8 \%$ of them made a complete recovery and regained the ability to walk independently. However, such review was limited by an insufficient number of patients with a long follow-up, leaving unsettled the question of whether deficits following ICUAW were persistent [21]. Since then, no extensive study investigating the functional outcome in these subjects have been carried out, and the issue remains unsolved. The aim of the present review was to investigate recovery, in particular the long-term functional outcome of subjects with ICUAW, whether the types of ICUAW have different outcomes and whether there is any supporting evidence.

\section{Materials and methods}

A search of the studies having tested the functional outcome in subjects with ICUAW was conducted using MEDLINE/PubMed, the Cochrane Central Register of Controlled Trials, CINAHL, EMBASE, PeDro, Web of Science and Scopus databases. The search was restricted to English language reports published between January 1984 and April 2021. The search terms varied slightly from database to database but included "intensive care unit acquired weakness", "ICUAW", "critical illness polyneuropathy", "CIP", "critical illness myopathy", "CIM", "critical polyneuropathy and myopathy", "CIPNM", "CIP and CIM"; "CIP/CIM", "acute tetraplegia", "rehabilitation", "functional outcome", "recovery", "physical therapy" and "mobilization". Search limits included only adults. Conference abstracts/posters or articles that were not peer-reviewed were excluded. The literature search was conducted by three independent authors (MC, MB, FDR). Inclusion criteria were: i) sample size including five or more subjects; ii) subjects who suffered from ICUAW and/or the following types: CIP, CIM and CIP/CIM; iii) ICUAW ascertained by EMG; iv) studies with mixed samples that used the definition of ICUAW, but subjects with CIP, CIM or CIP/CIM were also considered; v) follow-up and outcome.

In order to avoid confounding results, studies were excluded if: i) they contained only the definition of the ICUAW, without any reference to the types of ICUAW or to CIP, CIM or CIP/CIM; ii) ICUAW was not ascertained by EMG; iii) reviews concerned ICUAW but the main aim of the study was not the outcome. Studies concerning children were excluded as well as subjects with ICUAW and COVID-19.

We defined as long-term follow-ups those follow-ups longer than 1 year. In this review, the pathological condition was counted as CIP if this acronym or definition was not specified in the studies analyzed. Due to the variability of the study designs, the functional measurements, the follow-ups, and the lack of data on the score of measurements, quantitative analysis was not possible. The research was conducted according to the Preferred Reporting Items for Systematic Reviews and the MetaAnalyses (PRISMA) diagram, depicting the selection of the articles searched for the study. 


\section{Results}

The Prisma diagram of the studies' selection is shown in Fig. 1. After studies were searched for and collected, 36 of them were considered eligible; of these, 29 [2, 6, 22-48] were included according to inclusion and exclusion criteria (Table 1). Seven studies [49-55] were excluded even if they included subjects with ICUAW (Appendix 1). In particular, 4 of these 7 studies were excluded because they contained a duplicate of the data already included in the 29 studies, where they were analyzed in a greater sample [48-51]; 1 study with a large sample, due to the diagnosis of ICUAW being based predominantly on the clinical examination [52]; 2 studies including ICU patients having been discharged with the ICD-9/ICD-10 code for CIP and CIM (53-55) and did not use functional scale scores $[52,53]$. The included studies varied in aim, methodology design, sample size, case mix, inclusion/ exclusion criteria, timing of the examination, follow-up and definition of recovery. Seventeen (58.6\%) studies had a prospective design. Twenty-four (82.7\%) studies concerned case series or small cohorts that had a mean sample size of $19.1 \pm 7.7$ patients and did not exceed the total number of 30 subjects. The other 5 studies [35, 41, $44,45,48$ ] had samples greater than 30 patients (range 36-119) (Table 1). A total of 788 subjects with ICUAW were enrolled; of these 159 (20.1\%) died and 588 (74.6\%)

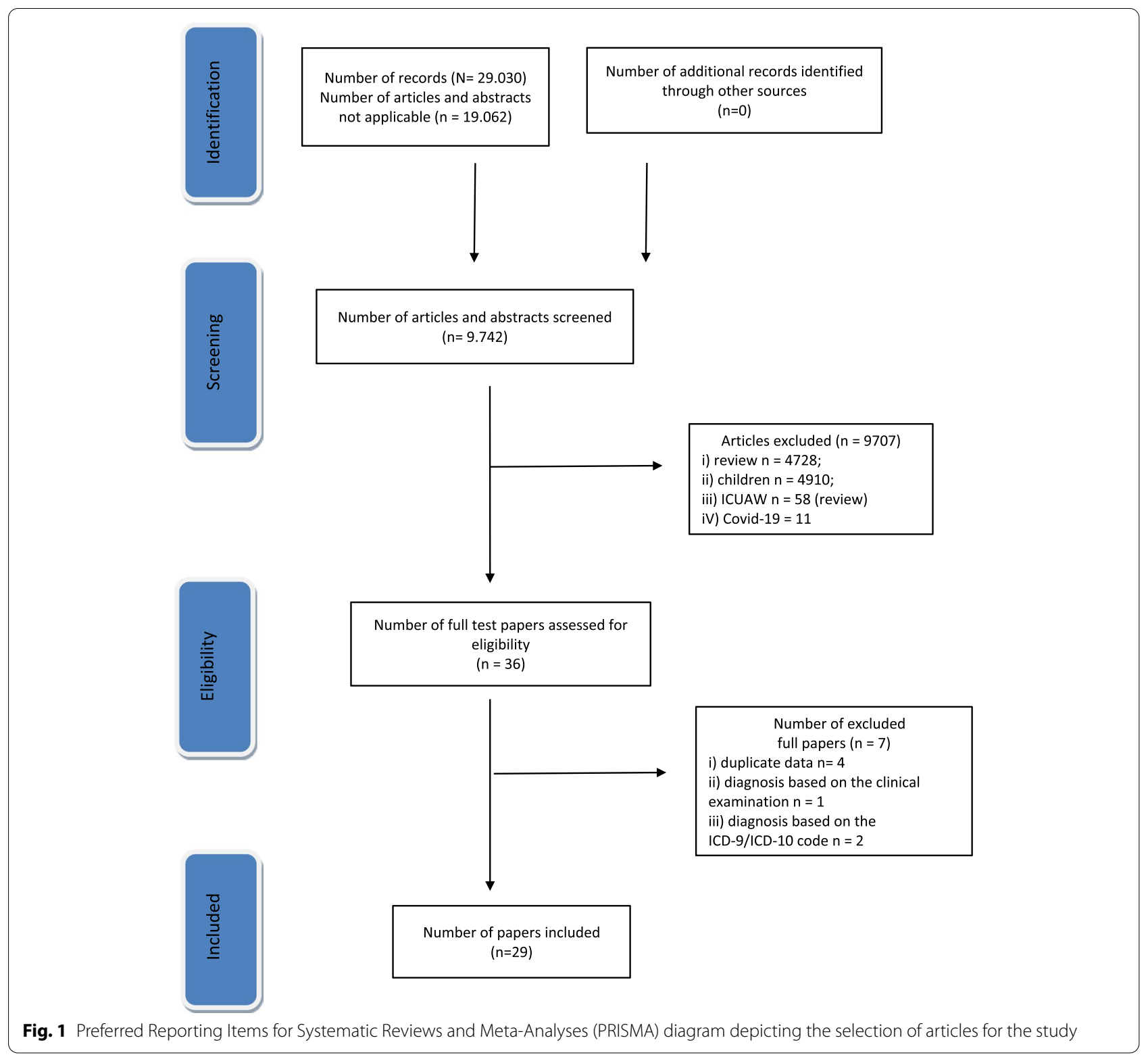




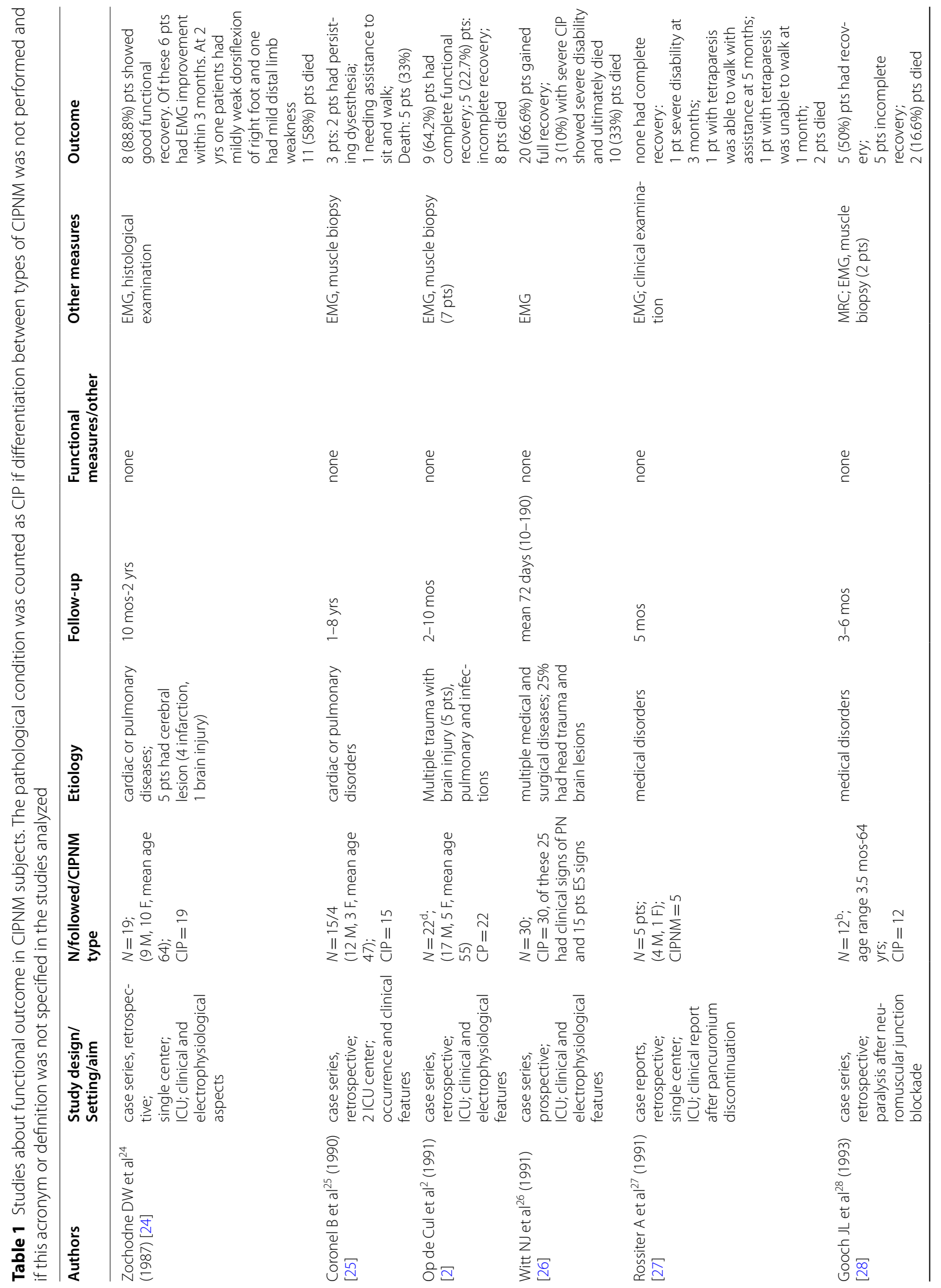




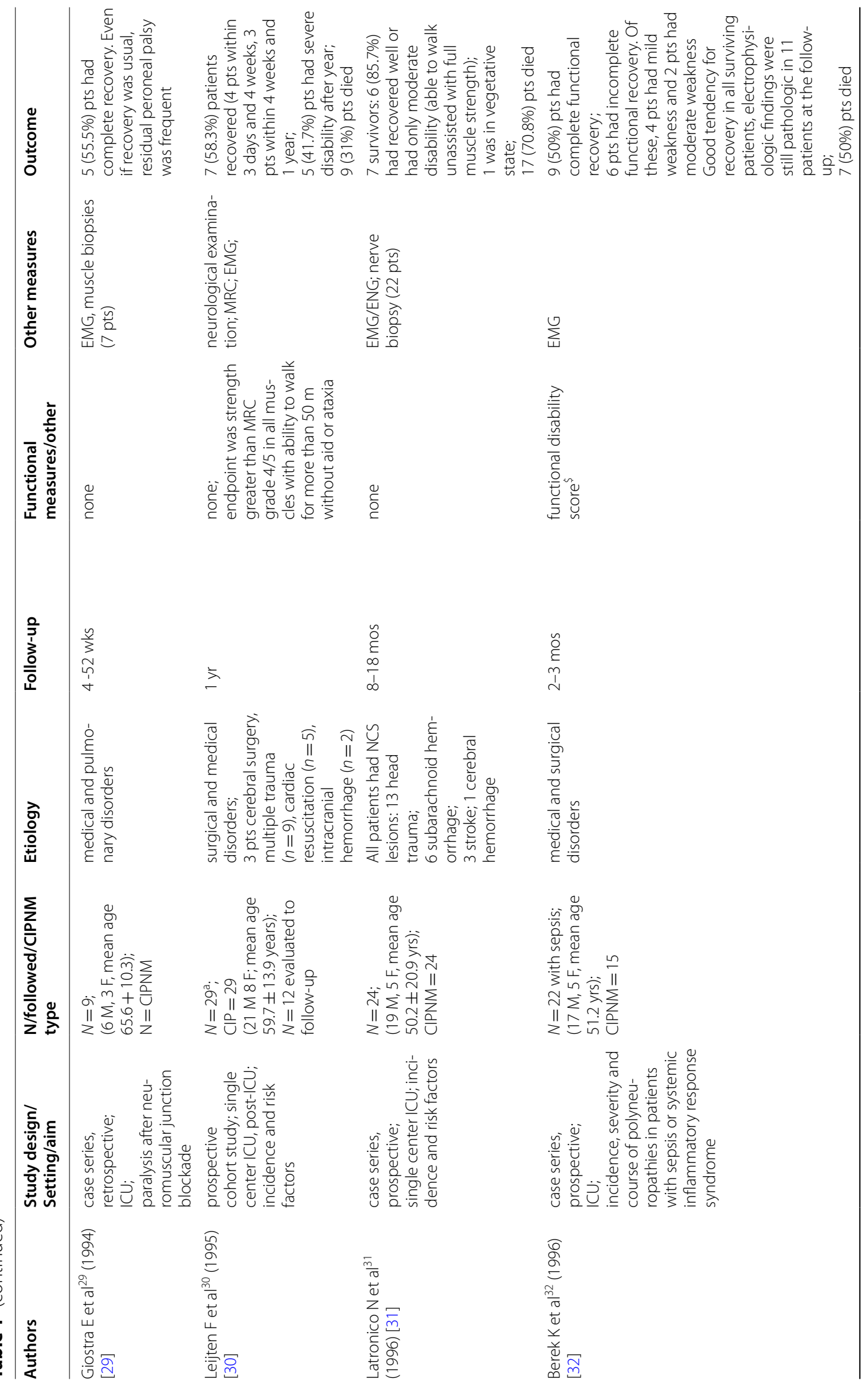




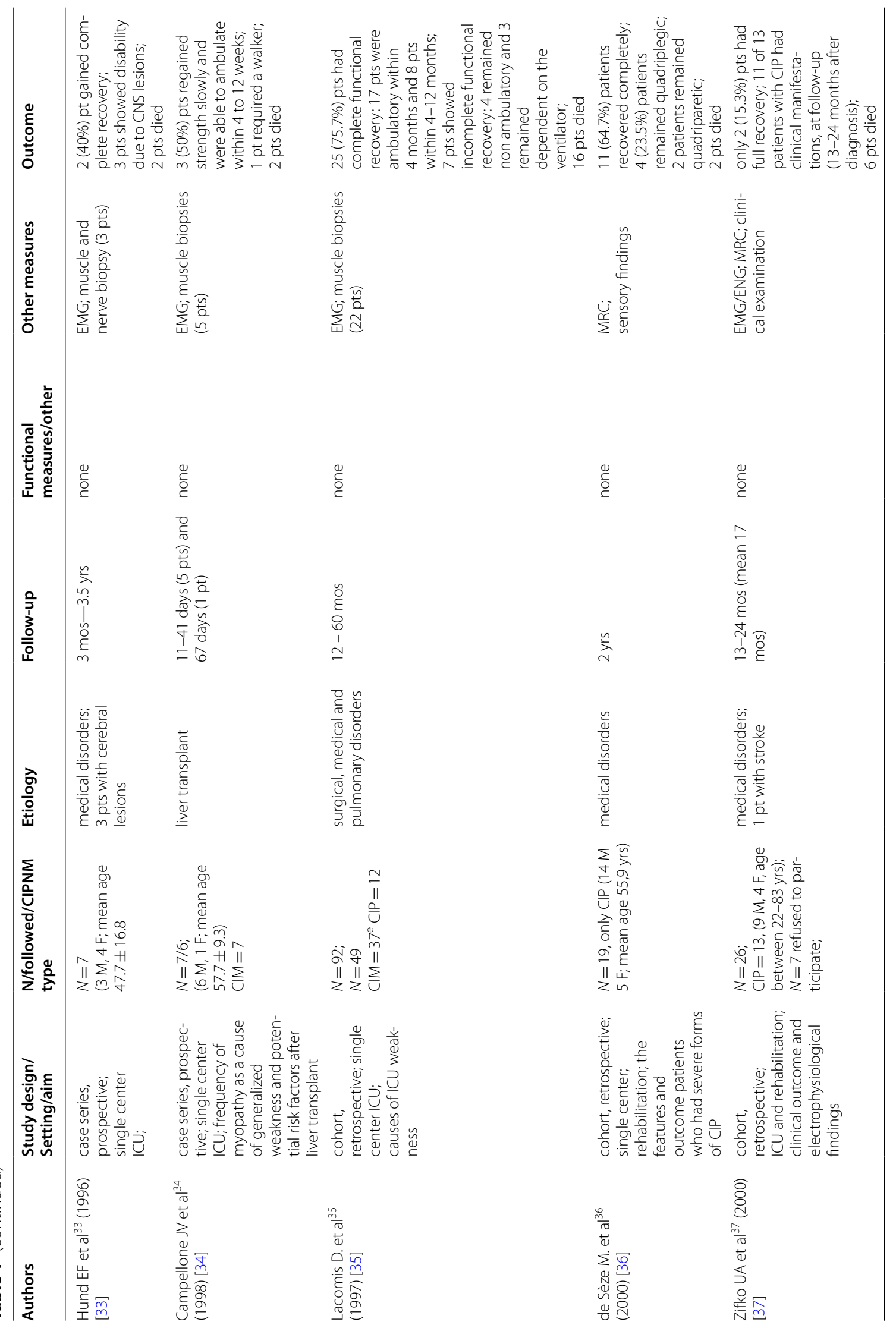




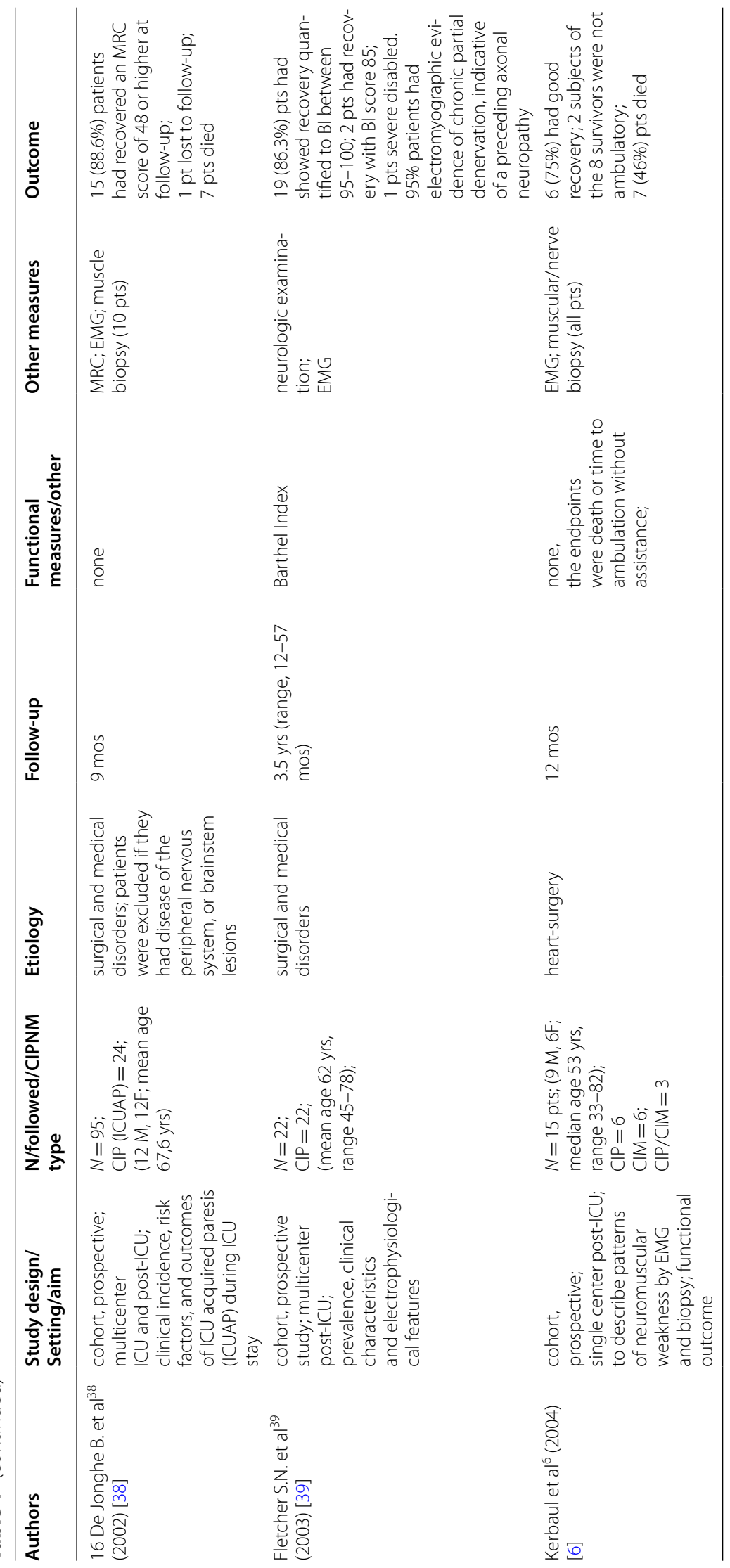




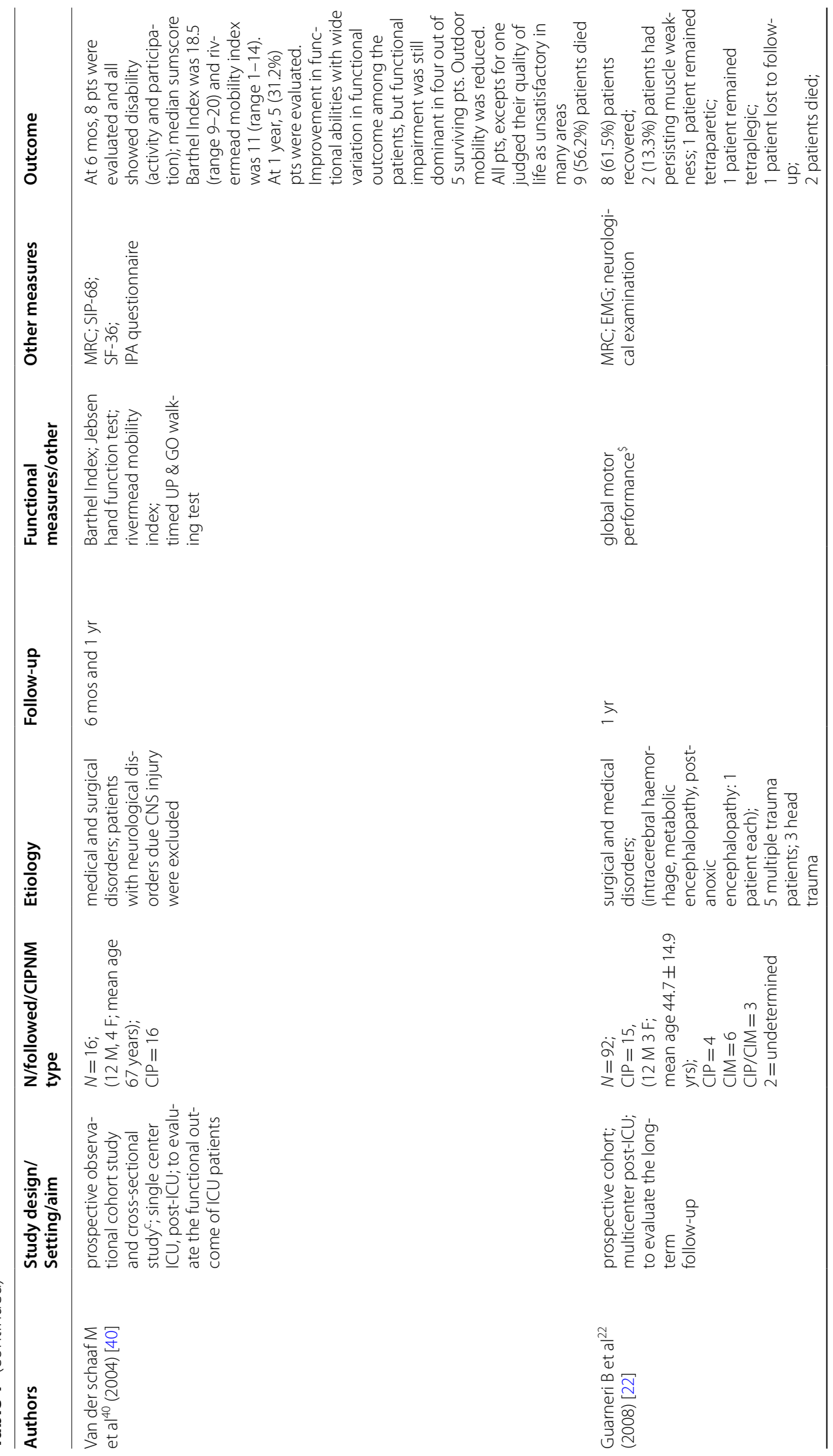




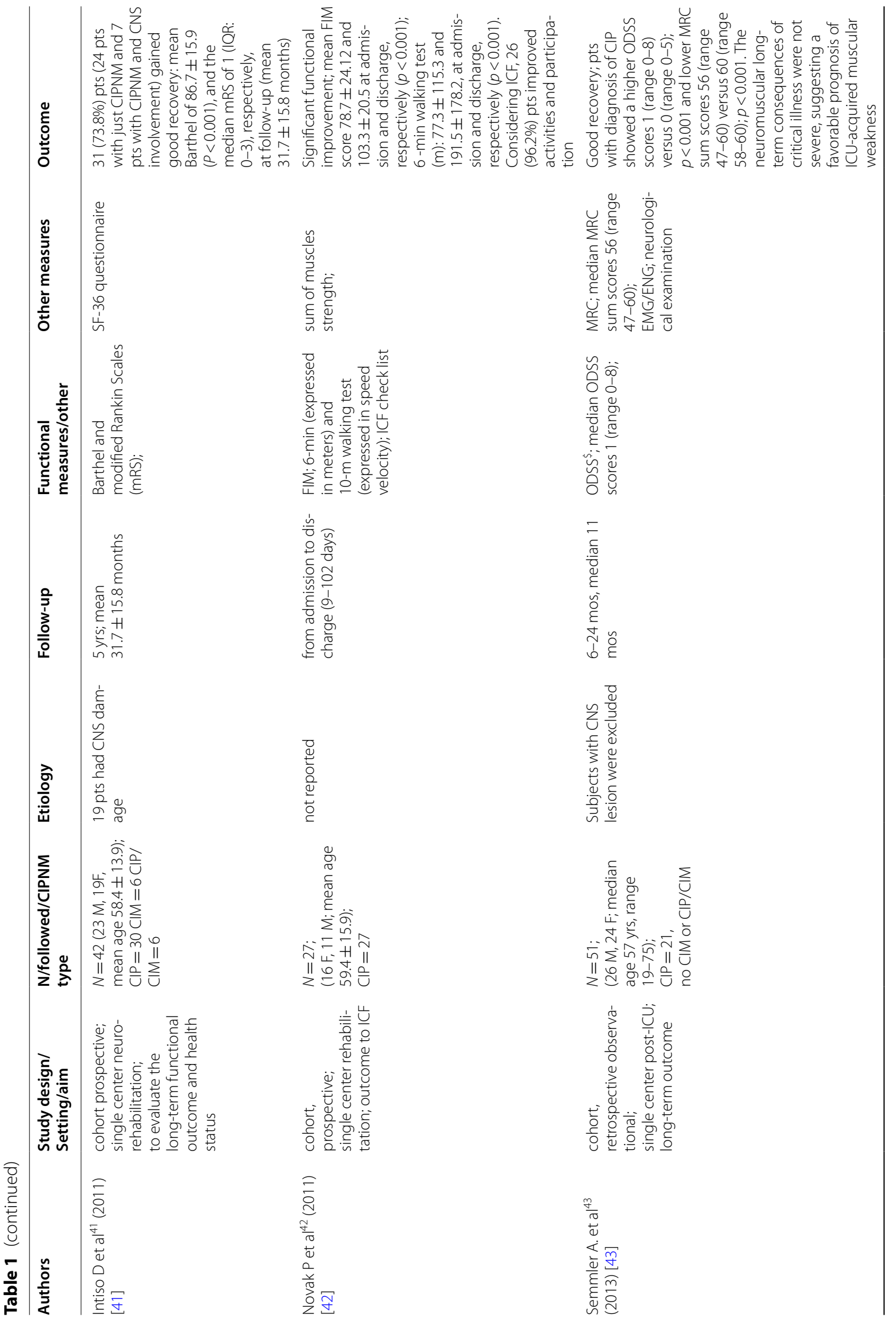




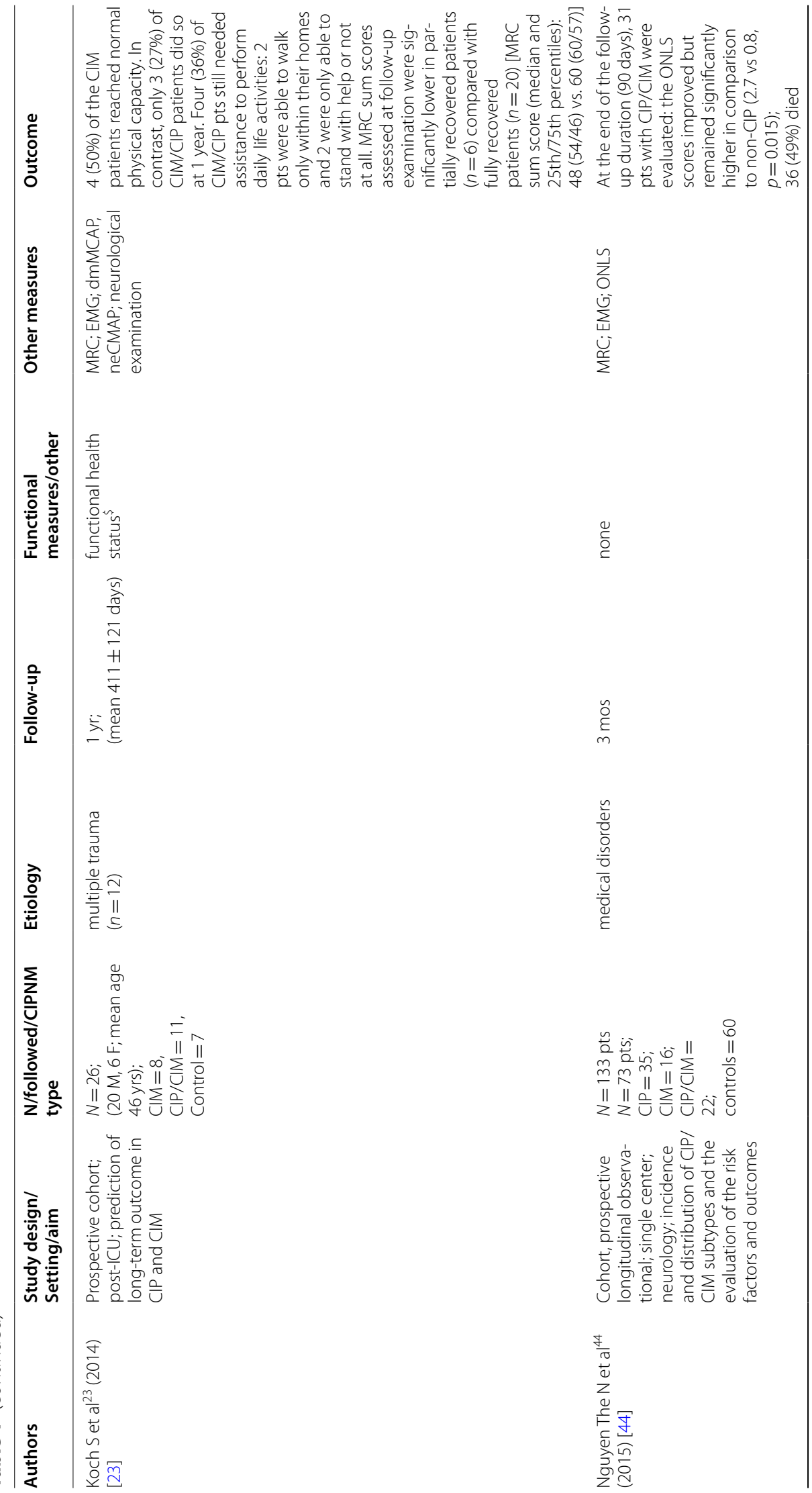




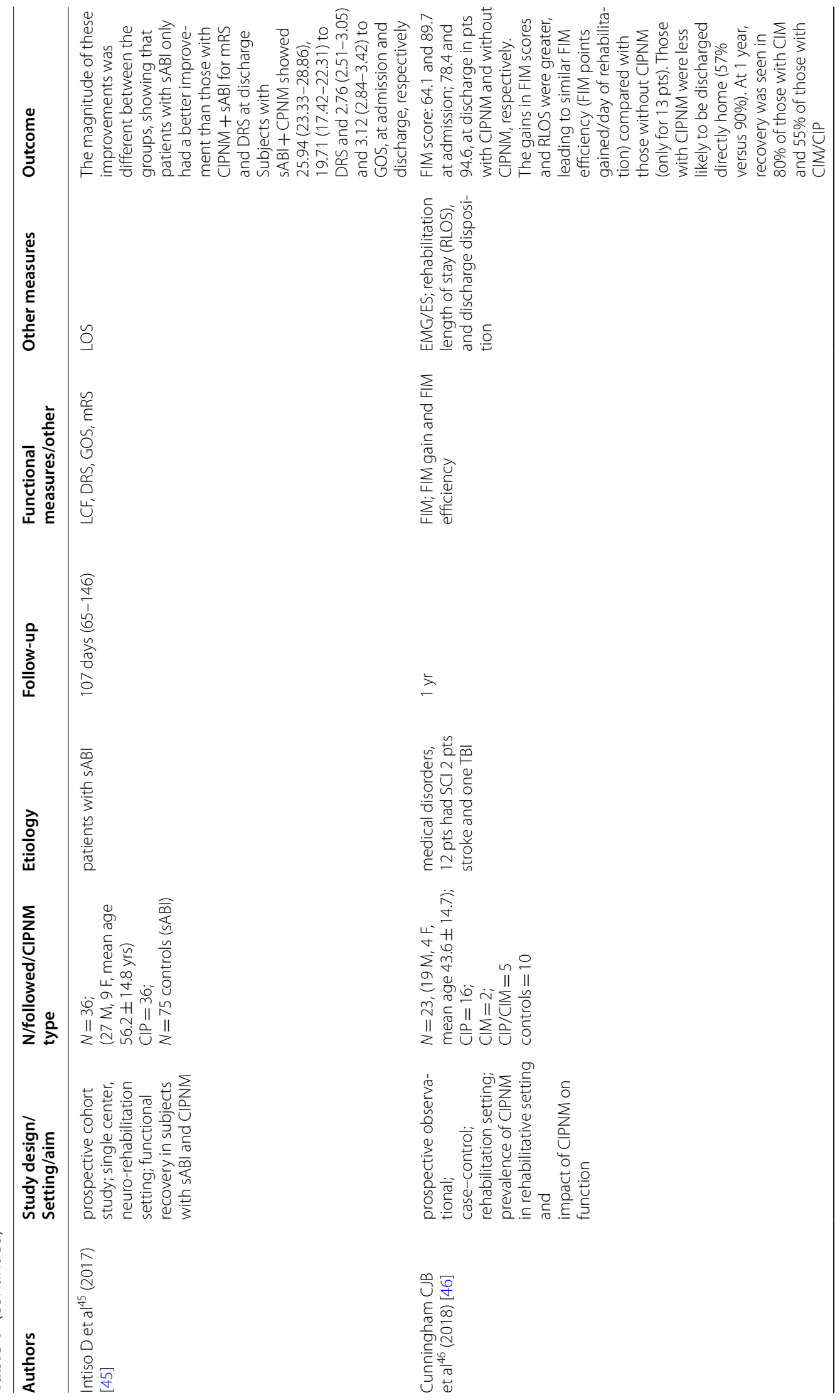




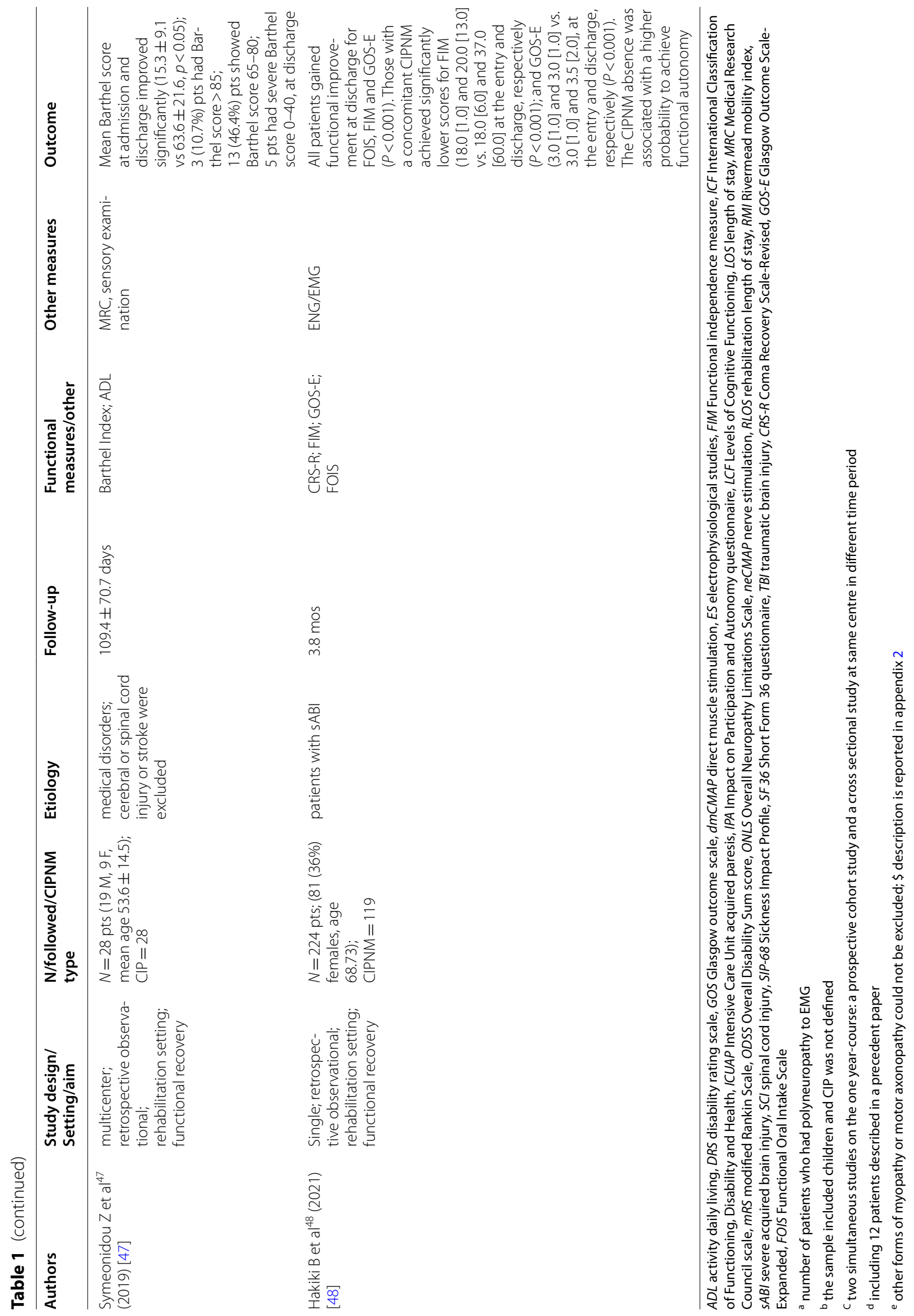


were followed. All studies except 7 [6, 22, 23, 35, 41, $44,46]$ did not perform the differentiation between the types of ICUAW and considered the disorder as a unique entity, labelling it as CIP or, more generically, as polyneuropathy or neuromuscular disorder. In particular, 613 (77.7\%) patients had CIP, 82 (10.4\%) CIM and 56 (7.1\%) CIP/CIM. Diagnoses requiring ICU admission were widely and due to variable medical and surgical disorders. Two studies investigated the functional outcome in patients with ICUAW and coexistent brain lesions $[45,48]$. Twenty $(68.9 \%)$ studies were performed on subjects during their ICU or post-ICU stay, 1 in neurology and $8(27.5 \%)$ in rehabilitation or in neuro-rehabilitative settings.

\section{Functional outcomes}

Determining the functional outcome was the main purpose of 9 (31\%) studies [22, 23, 40-43, 45, 47, 48]. Overall, $70.3 \%$ of subjects with ICUAW achieved a full recovery. Eighteen studies reported a percentage above $50 \%$ and among these, 10 showed that $75 \%$ of the sample (range 75-100) reached a full recovery. Functional measures were variable and overall, 16 tools were used to evaluate recovery: the Barthel Index (39-41, 47), the Functional Independence Measure (FIM) [42, 46, 48], the modified Rankin scale (mRS) $[41,45]$, the activity daily living scale (ADL) [47], the Disability Rating scale (DRS) [45], the Glasgow outcome scale (GOS) [45], Glasgow Outcome Scale Extended (GOS-E) [48]; the Coma Recovery ScaleRevised (CRS-R) [48]; the Rivermead Motor Assessment Scale (RMA) (40), the functional disability, the Jebsen hand function test [40], the timed UP \& GO walking test [40], the global motor performance [22], the 6-min (expressed in meters) and 10-m walking test (expressed in speed velocity) [42], the Overall Disability Sum score (ODSS) [43], and the Functional Health Status [23]. The Barthel Scale and the FIM were employed in 4 [39-41, 47] and 3 studies [42, 46, 48], respectively. The studies that used the Barthel scale showed contrasting findings. Of these, 2 prospective studies reported that $86.3 \%$ and $73.8 \%$ of the sample, respectively, achieved a good recovery (mean Barthel score > 90) at follow-up [39, 41]. Conversely, $10.7 \%$ and $31.2 \%$ of subjects made a full recovery in the remaining 2 studies [40, 47], respectively. The studies that used the FIM showed a significant functional improvement. In this regard, Novak et al. reported that subjects with CIP had a mean FIM score of $78.7 \pm 24.12$ and $103.3 \pm 20.5$, at admission and discharge, respectively $(p<0.001)$ [42]. Likewise, a prospective observational case control study by Cunningham et al. found that subjects with ICUAW had greater gains in FIM scores, leading to similar FIM efficiency (FIM points gained/day of rehabilitation), than subjects without ICUAW [46].
However, despite these seemingly functional improvements and similar discharge FIM scores, subjects with ICUAW were less likely to be discharged directly home (57\% versus $90 \%)$.

Fourteen (48.2\%) studies did not have patient's global ability as primary end-point and did not use functional scales. Recovery was evaluated from a clinical point of view by neurological examination or on the basis of the improvement in muscle strength by the MCR scale. This measure was used in 11 studies [22, 23, 28, 30, 36, 38, 40, $42-44,47]$. The severity of muscle weakness was not correlated with the clinical and electrophysiological diagnosis, and there was no correlation between the degree of the nerve conduction and the clinical findings $[22,37]$.

\section{Long-term outcomes}

Seven studies (24.1\%) had a follow-up longer than 1 year, ranging from 2 to 8 years (Table 2) for a total of $173(21.9 \%)$ subjects, of whom $37(21.3 \%)$ died and 108 were followed. Overall 124, 43 and 6 subjects had CIP, CIM and CIP/CIM, respectively. Of followed subjects with ICUAW 96 (88.8\%) achieved a full recovery. Almost all studies included small samples characterized by case series including 7 to 22 patients, and only 2 studies had greater samples consisting of 49 [35] and 42 subjects [41], respectively. Furthermore, the investigation of long-term functional outcomes in subjects with ICUAW as main purpose was addressed only in 1 of these 7 studies [41]. This study had a mixed sample and included 42 patients with different etiology of ICU admission and showed that $73.8 \%$ of the entire sample of patients made a good recovery, as shown by the functional measures at follow-up: mean Barthel and median mRS score of $86.7 \pm 15.9$ and 1 (IQR: 0-5), respectively. The differentiation between the types of CIPNM was performed only in 2 studies $[35,41]$. Both studies showed that subjects with CIP/CIM had the worst outcome. Functional measures were employed only in 2 studies that used the Barthel scale $[39,41]$ and the mRS [41]. Both studies had a long follow-up of 3.5 and 5 years, respectively, and a good recovery was detected in a high percentage of subjects. Five (71.4\%) studies did not use proper scales, and the recovery was evaluated by motor improvement, such as the ability to walk without support or aid.

\section{ICUAW type and outcome}

The differentiation between the types of ICUAW was performed in 7 (25\%) studies [6, 22, 23, 35, 41, 44, 46]. Among these, 3 investigations concerning the long-term functional outcome reported that the CIM type had a better prognosis and an earlier recovery than CIP/CIM [22, 23, 41]. In detail, Koch et al. enrolled a cohort of 26 subjects consisting of 11 and 8 patients with CIP/CIM 


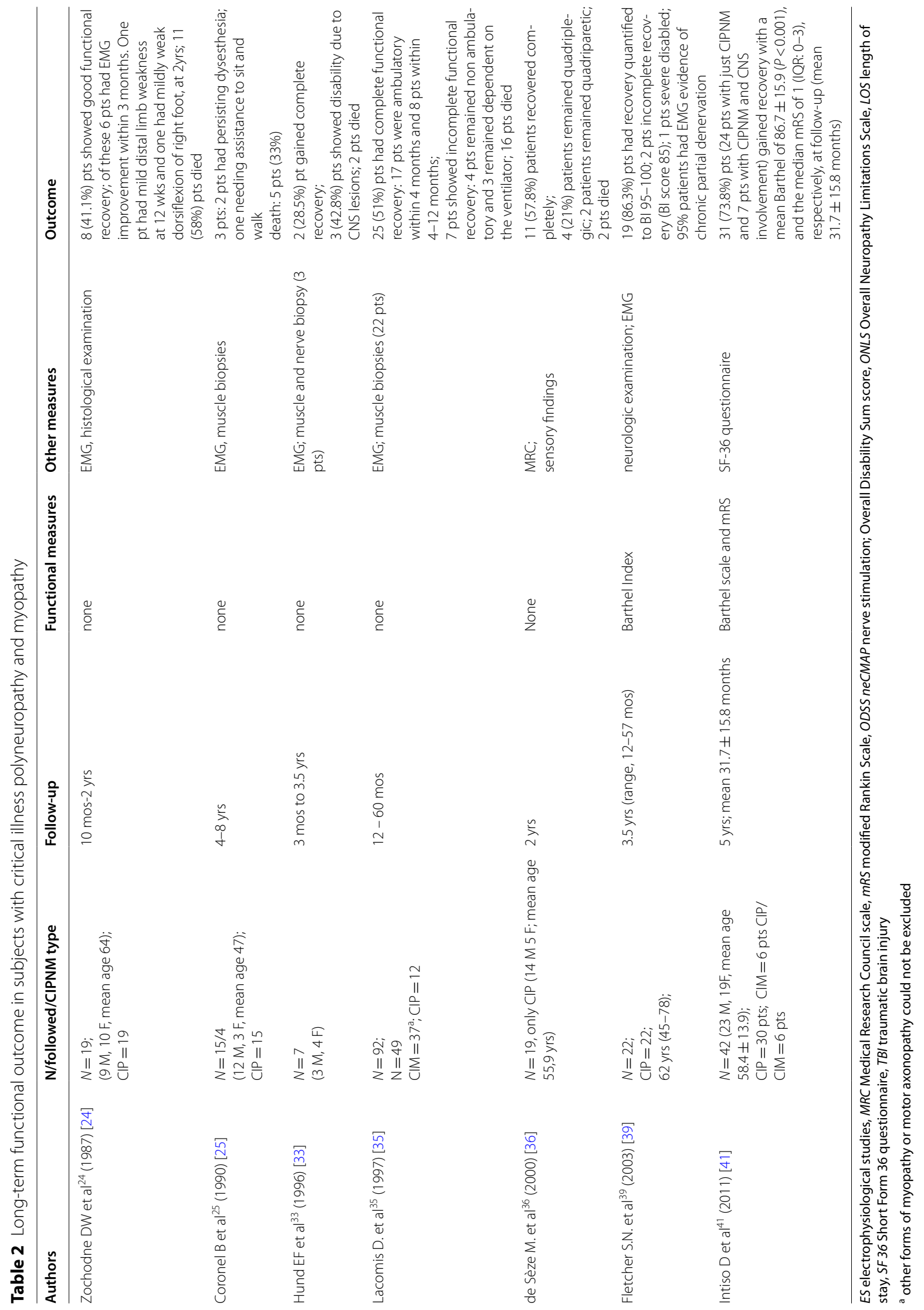


and CIM, respectively, whereas the remaining 7 were controls. After 1 year of follow up, in 7 (87.5\%) and 6 (54.5\%) patients with CIM and CIP/CIM, respectively, a return to normal physical capacity and a normal EMG were observed. Furthermore, 50\% of CIM patients recovered within 3 months, returning to a normal or at least a sufficient physical capacity to resume daily life activities. On the other hand, 5 (45.5\%) patients with CIP/ CIM had a partial recovery and abnormal electrophysiological findings. Guarneri et al. reported the long-term recovery of 15 patients with ICUAW and, of these, 4, 6 and 3 patients had CIP, CIM and CIP/CIM, respectively, whereas 2 subjects were undetermined. Five subjects with CIM recovered within 6 months, whereas the presence of CIP alone or in addition to CIM was associated with a more delayed recovery between 6 and 12 months, and more than $50 \%$ of those individuals had persistent deficits at 1 year of follow-up [22]. Likewise, the study by Intiso et al. reported that CIM patients had a better recovery than subjects with CIP or CIP/CIM and did not show differences in their health status compared to the Italian normative data. Of the remaining 4 studies, 3 did not report data on the recovery of ICUAW types, since ICUAW subjects were evaluated in comparison to controls independently of the type of ICUAW [6, 44, 46], and the last one had severe limitations despite the differentiation between the types of ICUAW, since other forms of myopathy or motor axonopathy could not be excluded [35].

\section{Discussion}

The present review detected that $70.3 \%$ of a large number subjects with ICUAW could achieve a good recovery. This finding is similar to that obtained from a previous review by Latronico et al., who reported that $68.8 \%$ of patients made a complete recovery [21]. Furthermore, a higher percentage of $88.8 \%$ gained good recovery at long term follow-up. However, because of strong limitations of studies that had small samples and were widely variable in aim, methodology design, case mix, and outcome measures, the finding should be considered with caution. The investigation of the functional outcome was the main purpose in $31 \%$ of the studies analyzed; in addition, a variety of measures was employed, and only 7 (24.1\%) studies used a proper functional scale such as the Barthel scale and the FIM.

Of great importance, immediately after the rehabilitation treatment, is the overall health status of the patients, culminating in a return to active daily living, socialization and participation. The International Classification of Functioning, Disability and Health (ICF) recommends a new approach to evaluate disabled people, which is based on a holistic model in which activities and participation represent essential aspects. In this respect, only 2 studies investigated the outcome according to the ICF, but because of the small size of the samples and the limited duration of the follow-ups, it was not possible to draw definitive conclusions [40, 42]. Most studies (71.4\%) evaluated recovery on the basis of the motor improvement and the ability to walk without support, but no data was reported on the functionality in activity daily living. Furthermore, though the present review retrieved a larger number of 788 patients with ICUAW, those who had long term follow-up for more than 1 year were only 173 (21.9\%) subjects.

Over two decades, until year 2000, the main purpose of investigators was to characterize the new clinical phenomenon. There were no studies having patient's global ability and quality of life as primary end-points. The majority of these studies reported the outcome in terms of complete or incomplete recovery (30-31, 35-36), motor performance [30, 31] and ambulatory activity $[6,30,35]$. The outcome was also addressed, but it was generically labeled as "full recovery" or based on the achievement of the motor ability, particularly of ambulation without support or aid. A proper functional scale quantifying disability and evaluating the patients' health status and quality of life was not employed. The evaluation of the functional outcome was performed on the neurological examination or on the improvement of the muscle strength by the MCR scale. Clinical recovery was considered complete if patients had an MRC grade of $4 / 5$ in all muscles $(22,30)$. Although this scale has been recently demonstrated to be an important predictor of death and of a worse five-year survival [56], it was designed and validated to quantify muscle strength impairment but not in relation to functional abilities. Most studies were performed by ICU specialists, and this may explain the methodological approach used. In this respect, ICU specialists might prefer to assess muscle weakness and to diagnose early ICUAW during the ICU stay, since this disorder could be a severe complication for the weaning of mechanical ventilation $[57,58]$ and could delay ICU discharge.

Some authors suggested that patients with the Central Nervous System (CNS) injury might likewise develop critical illness polyneuropathy and, consequently, recovery might be hampered by the CNS damage (33, 35); however, only $4(14.2 \%)$ studies $[38,40,43,47]$ excluded subjects with the CNS damage to avoid confounding findings on the outcome. On the other hand, 2 studies were designed to investigate recovery in subjects with severe acquired brain injuries (sABI) and coexistent ICUAW $[45,48]$. The authors reported that patients with SABI and ICUAW achieved a good recovery, but the magnitude of these improvements was better in the 
subjects with sABI alone. However, it is still not clear if the residual disability in these subjects is due predominantly to ICUAW, to CNS damage or to both disorders. Likewise, the effect that each disease might have on the course of the disability still needs to be clarified. People with both disorders might require different rehabilitation approaches and strategies.

It has been suggested that subjects with CIM have a better prognosis, reaching early and full recovery, than subjects with CIP or CIP/CIM, but this finding was reported only in 3 studies including a total of 20 patients $[22,23,41]$. Therefore, it is not possible to achieve a definitive conclusion about this matter due to the very small number of investigated subjects. Several difficulties hamper and make it hard to make real and objective comments on this issue. Some of these difficulties are the lack of unique and shared definitions of muscle weakness that may affect ICU subjects as well as an insufficient differentiation between the types of ICUAW. Today, a wide range of definitions are still being used including ICUAW, CIP, CIM, CIP/CIM or CIPNM, and this aspect can complicate the analysis, and the results of the studies may be consequently biased. Most investigations considered this disorder as a single entity, therefore it is not possible to exclude that different forms of ICUAW were present in the sample of the studies investigating only subjects with CIP. Furthermore, although EMG is able to differentiate between the subtypes of ICUAW, it does not allow the quantification of the muscle impairment and the related disabilities, and no electrophysiological exams or imaging have helped to solve this point.

\section{Limitations}

The present study has limitations that must be acknowledged. This is a review of the literature having the aim to discuss the recovery and the long-term functional outcome of ICUAW subjects. Cohort studies, case series as well as functional measurements and followup were highly heterogeneous regarding the functional outcome. A further limitation concerns the recovery of subjects with ICUAW, such limitation is due to the paucity of trials focusing on rehabilitative interventions $[41,42,59]$. Even if this issue is beyond the scope of the present review, the majority of the studies analyzed did not define whether the subjects followed any kind of rehabilitation treatment after hospital discharge. Currently, apart from the early neuromuscular electrical stimulation that might prevent ICUAW and improve the quality of life by enhancing muscle strength in ICU patients [59], no definitive studies have evaluated the effects of rehabilitation programs in inpatient or outpatient settings in this population [60]. Therefore, several questions remain unanswered and further research should be carried out on this matter.

\section{Suggestions and implications for the future}

Given the protean aspects of ICUAW, a closer collaboration as well as a more active participation of multiple specialists and experts has been suggested [61]. In particular, ICU specialists, neurologists and physiatrists should collaborate more to properly evaluate and follow these subjects. Specialists who manage ICUAW patients should adopt unique and shared terminology and definitions, and future studies should be planned considering the following aspects:

1- the aim should be focused on functional recovery; the methodology design should include a large sample of patients, proper functional measures and defined long-term follow-up;

2- differentiation between the types of ICUAW;

3- rehabilitation interventions and their effect on functional outcome and quality of life, given that few studies have evaluated the effects of rehabilitation programs in this population.;

4- Occurrence and recovery of ICUAW in subjects with CNS damage should be investigated through dedicated studies.

\section{Conclusion}

A percentage of $70.3 \%$ of survivor subjects with ICUAW could achieve a good recovery and a higher percentage was detected at long term follow-up. However, the quality of the published studies due to short follow-ups, and the absence of clearly defined outcome measures did not allow definitive conclusions. A close collaboration between specialists and proper planned research in this field are needed to answer the unsolved questions.

\section{Abbreviations}

ADL: Activity of daily living; DRS: Disability rating scale; GOS: Glasgow outcome scale; dmCMAP: Direct muscle stimulation; ES: Electrophysiological studies; FIM: Functional independence measure; ICF: International Classification of Functioning, Disability and Health; ICUAP: Intensive Care Unit acquired paresis; IPA: Impact on Participation and Autonomy questionnaire; LCF: Levels of Cognitive Functioning; LOS: Length of stay; MRC: Medical Research Council scale; mRS: Modified Rankin Scale; ODSS: Overall Disability Sum score; ONLS: Overall Neuropathy Limitations Scale; neCMAP: Nerve stimulation; RLOS: Rehabilitation length of stay; RMI: Rivermead mobility index; SABI: Severe acquired brain injury; SCI: Spinal cord injury; SIP-68: Sickness Impact Profile; SF 36: Short Form 36 questionnaire; TBI: Traumatic brain injury; CRS-R: Coma Recovery Scale-Revised; GOS-E: Glasgow Outcome Scale-Expanded; FOIS: Functional Oral Intake Scale. 


\section{Supplementary Information}

The online version contains supplementary material available at https://doi. org/10.1186/s12883-022-02570-z.

Additional file 1: Appendix 1

Additional file 2: Appendix 2

\section{Acknowledgements}

Not Applicable"

\section{Authors' contributions}

Conceptualization: DI, FDR; Data extraction: MC; MB, MTG; MG; Manuscript preparation: DI, MB, FDR; Review and revision: DI, FDR. All authors have read and agreed to the version of the manuscript.

\section{Funding}

The authors received no financial support for the research, authorship, and/or publication of this article.

\section{Availability of data and materials}

All data generated or analysed during this study are included in this published article [and its supplementary information files]

The datasets used and/or analysed during the current study available from the corresponding author on reasonable request.

\section{Declarations}

Ethics approval and consent to participate

Not Applicable

\section{Consent for publication}

Not Applicable

\section{Competing interests}

The authors declare that there is no conflict of interest with respect to the research, authorship, and/or publication of this article.

\section{Author details}

${ }^{1}$ Unit of Neuro-Rehabilitation and Rehabilitation Medicine, IRCCS "Casa Sollievo della Sofferenza", Viale dei Cappuccini, 71013 San Giovanni Rotondo (FG), Italy. ${ }^{2}$ Department of Rehabilitation, Neurorehabilitation Unit, Habilita Care \& Research, Zingonia (Bergamo), Italy.

Received: 30 September 2021 Accepted: 28 January 2022

Published online: 11 February 2022

\section{References}

1. Stevens RD, Marshall SA, Cornblath DR, Hoke A, Needham DM, de Jonghe B, Ali NA, Sharshar T. A framework for diagnosing and classifying intensive care unit-acquired weakness. Crit Care Med. 2009;37(10 Suppl):S299-308

2. Op de Coul AA, Verheul GA, Leyten AC, et al. Critical illness polyneuromyopathy after artificial respiration. Clin Neurol Neurosurg. 1991;93:27-33.

3. Bednarik J, Lukas Z, Vondracek P. Critical illness polyneuromyopathy: the electrophysiological components of a complex entity. Intensive Care Med. 2003:29(9):1505-14.

4. Bolton CF, Gilbert JJ, Hahn AF, Sibbald WJ. Polyneuropathy in critically ill patients. J Neurol Neurosurg Psychiatry. 1984;47(11):1223-31.

5. Lefaucheur JP, Nordine T, Rodriguez P, Brochard L. Origin of ICU acquired paresis determined by direct muscle stimulation. J Neurol Neurosurg Psychiatry. 2006;77(4):500-6.

6. Kerbaul F, Brousse M, Collart F, Pelissier JF, Planche D, Fernandez C, Gouin F, Guidon C. Combination of histopathological and electromyographic patterns can help to evaluate functional outcome of critical ill patients with neuromuscular weakness syndromes. Crit Care. 2004;8(6):R358-66.
7. Hough CL, Steinberg KP, Taylor Thompson B, Rubenfeld GD, Hudson LD. Intensive care unit-acquired neuromyopathy and corticosteroids in survivors of persistent ARDS. Intensive Care Med. 2009:35:63-8.

8. de Jonghe B, Lacherade JC, Sharshar T, Outin H. Intensive care unit-acquired weakness: risk factors and prevention. Crit Care Med. 2009;37:S309-15

9. Stevens RD, Dowdy DW, Michaels RK, Mendez-Tellez PA, Pronovost PJ, Needham DM. Neuromuscular dysfunction acquired in critical illness: a systematic review. Intensive Care Med. 2007:33:1876-91.

10 Fan E, Cheek F, Chlan L, et al. An official American Thoracic Society Clinical Practice guideline: the diagnosis of intensive care unit-acquired weakness in adults. Am J Respir Crit Care Med. 2014;190(12):1437-46.

11. Bednarík J, Vondracek P, Dusek L, Moravcova E, Cundrle I. Risk factors for critical illness polyneuromyopathy. J Neurol. 2005;252(3):343-51.

12. Nanas S, Kritikos K, Angelopoulos E, Siafaka A, Tsikriki S, Poriazi M, Kanaloupiti D, Kontogeorgi M, Pratikaki M, Zervakis D, Routsi C, Roussos C. Predisposing factors for critical illness polyneuromyopathy in a multidisciplinary intensive care unit. Acta Neurol Scand. 2008;118(3):175-81.

13 Hermans G, De Jonghe B, Bruyninckx F, Van den Berghe G. Interventions for preventing critical illness polyneuropathy and critical illness myopathy. Cochrane Database Syst Rev. 2014;1:CD006832.

14 Shepherd SJ, Newman R, Brett SJ, Griffith DM. Enhancing Rehabilitation after Critical IIIness Programme Study Investigators. Pharmacological therapy for the prevention and treatment of weakness after critical illness: A systematic review. Crit Care Med. 2016;44(6):1198-205.

15. Zayed Y, Kheiri B, Barbarawi M, Chahine A, Rashdan L, Chintalapati S, Bachuwa G, Al-Sanouri I. Effects of neuromuscular electrical stimulation in critically ill patients: A systematic review and meta-analysis of randomised controlled trials. Aust Crit Care. 2020;33(2):203-10.

16 Anekwe DE, Biswas S, Bussières A, Spahija J. Early rehabilitation reduces the likelihood of developing intensive care unit-acquired weakness: a systematic review and meta-analysis. Physiotherapy. 2020;107:1-10.

17. Zhang L, Hu W, Cai Z, Liu J, Wu J, Deng Y, Yu K, Chen X, Zhu L, Ma J, Qin $Y$. Early mobilization of critically ill patients in the intensive care unit: $A$ systematic review and meta-analysis. PLoS One. 2019;14(10):e0223185.

18 Hermans G, Van den Berghe G. Clinical review: intensive care unit acquired weakness. Crit Care. 2015;19(1):274.

19. Piva S, Fagoni N, Latronico N. Intensive care unit-acquired weakness: unanswered questions and targets for future research. F1000Res. 2019;8:F1000 (Faculty Rev-508)

20. Vanhorebeek I, Latronico N, Van den Berghe G. ICU acquired weakness. Intensive Care Med. 2020;46(4):637-53.

21. Latronico N, Shehu I, Seghelini E. Neuromuscular sequelae of critical illness. Curr Opin Crit Care. 2005;11(4):381-90.

22. Guarneri B, Bertolini G, Latronico N. Long-term outcome in patients with critical illness myopathy or neuropathy: the Italian multicentre CRIMYNE study. J Neurol Neurosurg Psychiatry. 2008;79(7):838-41.

23. Koch S, Wollersheim T, Bierbrauer J, Haas K, Mörgeli R, Deja M, Spies CD, Spuler S, Krebs M, Weber-Carstens S. Long-term recovery In critical illness myopathy is complete, contrary to polyneuropathy. Muscle Nerve. 2014;50(3):431-6

24 Zochodne DW, Bolton CF, Wells GA, et al. Critical illness polyneuropathy. A complication of sepsis and multiple organ failure. Brain. 1987;110:819-41.

25. Coronel B, Mercatello A, Couturier JC, et al. Polyneuropathy: potential cause of difficult weaning. Crit Care Med. 1990;18:486-9.

26. Witt NJ, Zochodne DW, Bolton CF, et al. Peripheral nerve function in sepsis and multiple organ failure. Chest. 1991;99:176-84.

27. Rossiter A, Souney PF, McGowan S, et al. Pancuronium-induced prolonged neuromuscular blockade. Crit Care Med. 1991;19:1583-7.

28. Gooch JL, Moore MH, Ryser DK. Prolonged paralysis after neuromuscular junction blockade: case reports and electrodiagnostic findings. Arch Phys Med Rehabil. 1993:74(9):1007-11.

29 Giostra E, Magistris MR, Pizzolato G, et al. Neuromuscular disorder in intensive care unit patients treated with pancuronium bromide. Occurrence in a cluster group of seven patients and two sporadic cases, with electrophysiologic and histologic examination. Chest. 1994;106:210-20.

30. Leijten FS, Harinck-de Weerd JE, Poortvliet DC, et al. The role of polyneuropathy in motor convalescence after prolonged mechanical ventilation. JAMA. 1995:274:1221-5. 
31. Latronico N, Fenzi F, Recupero D, Guarneri B, Tomelleri G, Tonin P, De Maria G, Antonini L, Rizzuto N, Candiani A. Critical illness myopathy and neuropathy. Lancet. 1996;347(9015):1579-82.

32. Berek K, Margreiter J, Willeit J, et al. Polyneuropathies in critically ill patients: a prospective evaluation. Intensive Care Med. 1996;22:849-55.

33. Hund EF, Fogel W, Krieger D, et al. Critical illness polyneuropathy: clinica findings and outcomes of a frequent cause of neuromuscular weaning failure. Crit Care Med. 1996;24:1328-33.

34. Campellone JV, Lacomis D, Kramer DJ, et al. Acute myopathy after liver transplantation. Neurology. 1998;50:46-53.

35. Lacomis D, Petrella JT, Giuliani MJ. Causes of neuromuscular weakness in the intensive care unit: a study of ninety-two patients. Muscle Nerve. 1998;21:610-7.

36. de Seze M, Petit H, Wiart L, et al. Critical illness polyneuropathy. A 2-year follow-up study in 19 severe cases. Eur Neurol. 2000;43:61-9.

37 Zifko UA. Long-term outcome of critical illness polyneuropathy. Muscle Nerve. 2000;Suppl 9:S49-52

38. De Jonghe $B$, Sharshar $T$, Lefaucheur JP, et al. Paresis acquired in the intensive care unit: a prospective multicenter study. JAMA. 2002;288:2859-67.

39. Fletcher SN, Kennedy DD, Ghosh IR, et al. Persistent neuromuscular and neurophysiologic abnormalities in long-term survivors of prolonged critical illness. Crit Care Med. 2003;31:1012-6.

40. van der Schaaf M, Beelen A, Dongelmans DA, Vroom MB, Nollet F. Poor functional recovery after a critical illness: a longitudinal study. J Rehabil Med. 2009:41(13):1041-8.

41. Intiso D, Amoruso L, Zarrelli M, Pazienza L, Basciani M, Grimaldi G, larossi A, Di Rienzo F. Long-term functional outcome and health status of patients with critical illness polyneuromyopathy. Acta Neurol Scand 2011:123(3):211-9.

42. Novak P, Vidmar G, Kuret Z, Bizovičar N. Rehabilitation of critical illness polyneuropathy and myopathy patients: an observational study. Int J Rehabil Res. 2011;34(4):336-42.

43. Semmler A, Okulla T, Kaiser M, Seifert B, Heneka MT. Long-term neuromuscular sequelae of critical illness. J Neurol. 2013;260(1):151-7.

44 Nguyen The L, Nguyen HuuC. Critical illness polyneuropathy and myopathy in a rural area in Vietnam. J Neurol Sci. 2015;357(1-2):276-81.

45. Intiso D, Di Rienzo F, Fontana A, Tolfa M, Bartolo M, Copetti M. Functional outcome of critical illness polyneuropathy in patients affected by severe brain injury. Eur J Phys Rehabil Med. 2017;53(6):910-9.

46. Cunningham CJB, Finlayson HC, Henderson WR, O'Connor RJ, Travlos A. Impact of Critical IIIness Polyneuromyopathy in Rehabilitation: A Prospective Observational Study. PM R. 2018;10(5):494-500.

47. Symeonidou Z, Theodoraki K, Chalkias A, Argyra E, Casale R. Critical Illness Polyneuropathy (CIP): a multicenter study on functional outcome. G Ital Med Lav Ergon. 2019;41(1):58-64.

48. Hakiki B, Draghi F, Scarpino M, Portaccio E, Romoli A, Mannini A, Atzori T, Lolli F, Macchi C, Grippo A. Critical illness polyneuromyopathy: Functional impact after severe acquired brain injuries. Acta Neurol Scand. 2020;142(6):574-84

49. Op de Coul AA, Lambregts PC, Koeman J, van Puyenbroek MJ, Ter Laak HJ, Gabreëls-Festen AA. Neuromuscular complications in patients given Pavulon (pancuronium bromide) during artificial ventilation. Clin Neurol Neurosurg. 1985:87(1):17-22.

50. Gooch JL, Suchyta MR, Balbierz JM, et al. Prolonged paralysis after treatment with neuromuscular junction blocking agents. Crit Care Med. 1991;19:1125-31.

51. Lacomis D, Giuliani MJ, Van Cott A, et al. Acute myopathy of intensive care: clinical, electromyographic, and pathological aspects. Ann Neurol. 1996;40:645-54

52. Koch S, Spuler S, Deja M, Bierbrauer J, Dimroth A, Behse F, Spies CD, Wernecke KD, Weber-Carstens S. Critical illness myopathy is frequent: accompanying neuropathy protracts ICU discharge. J Neurol Neurosurg Psychiatry. 2011;82(3):287-93.

53. Schmidt SB, Rollnik JD. Critical illness polyneuropathy (CIP) in neurological early rehabilitation: clinical and neurophysiological features. BMC Neurol. 2016:16(1):256.

54. Kelmenson DA, Held N, Allen RR, Quan D, Burnham EL, Clark BJ, Ho PM, Kiser TH, Vandivier RW, Moss M. Outcomes of ICU Patients With a Discharge Diagnosis of Critical Illness Polyneuromyopathy: A PropensityMatched Analysis. Crit Care Med. 2017:45(12):2055-60.
55. Meyer-Frießem CH, Malewicz NM, Rath S, Ebel M, Kaisler M, Tegenthoff M, Schildhauer TA, Pogatzki-Zahn EM, Maier C, Zahn PK. Incidence, Time Course and Influence on Quality of Life of Intensive Care Unit-Acquired Weakness Symptoms in Long-Term Intensive Care Survivors. J Intensive Care Med 2020; 885066620949178. doi: https://doi.org/10.1177/08850 66620949178.

56. Van Aerde N, Meersseman P, Debaveye Y, Wilmer A, Gunst J, Casaer MP, Bruyninckx F, Wouters PJ, Gosselink R, Van den Berghe G, Hermans G. Fiveyear impact of ICU-acquired neuromuscular complications: a prospective, observational study. Intensive Care Med. 2020;46(6):1184-93.

57. De Jonghe B, Sharshar T, Hopkinson N, Outin H. Paresis following mechanical ventilation. Curr Opin Crit Care. 2004;10(1):47-52.

58. Garnacho-Montero J, Amaya-Villar R, García-Garmendía JL, MadrazoOsuna J, Ortiz-Leyba C. Effect of critical illness polyneuropathy on the withdrawal from mechanical ventilation and the length of stay in septic patients. Crit Care Med. 2005;2:349-54.

59. Liu M, Luo J, Zhou J, Zhu X. Intervention effect of neuromuscular electrical stimulation on ICU acquired weakness: A meta-analysis. Int J Nurs Sci. 2020;7(2):228-37.

60. Mehrholz J, Pohl M, Kugler J, Burridge J, Mückel S, Elsner B. Physical rehabilitation for critical illness myopathy and neuropathy. Cochrane Database Syst Rev. 2015;(3):CD010942. https://doi.org/10.1002/14651858. CD010942.pub2.

61. Intiso D. ICU-acquired weakness: should medical sovereignty belong to any specialist? Crit Care. 2018;22(1):1. https://doi.org/10.1186/ s13054-017-1923-7.

\section{Publisher's Note}

Springer Nature remains neutral with regard to jurisdictional claims in published maps and institutional affiliations.

Ready to submit your research? Choose BMC and benefit from

- fast, convenient online submission

- thorough peer review by experienced researchers in your field

- rapid publication on acceptance

- support for research data, including large and complex data types

- gold Open Access which fosters wider collaboration and increased citations

- maximum visibility for your research: over $100 \mathrm{M}$ website views per year

At BMC, research is always in progress.

Learn more biomedcentral.com/submissions 